\title{
Modeling the effects of climate change on eelgrass stability and resilience: future scenarios and leading indicators of collapse
}

\author{
Joel A. Carr*, Paolo D'Odorico, Karen J. McGlathery, Patricia L. Wiberg
}

University of Virginia Dept. of Environmental Sciences, 291 McCormick Rd, Clark Hall, Charlottesville, Virginia 22904, USA

\begin{abstract}
Seagrass meadows influence local hydrodynamics in coastal bays, resulting in a decrease in the shear stress acting on the underlying bed sediment. The reduced sediment suspension and water column turbidity creates a more favorable light environment for further seagrass growth. This positive feedback is strong enough to induce depth-dependent bistable dynamics with 2 possible stable states, an extant meadow and a bare sediment surface. A coupled vegetation-growth hydrodynamic model was used to investigate eelgrass stability and leading indicators of ecosystem shift under the effects of sea-level rise and increases in water temperature associated with climate change. The model was applied to Hog Island Bay, a shallow coastal bay within the Virginia Coast Reserve, USA, where eelgrass restoration efforts are ongoing. The results indicate that while extant eelgrass meadows are likely to tolerate sea-level rise, an increase in the frequency of days when summer water temperature exceeds $30^{\circ} \mathrm{C}$ will cause more frequent summer die-offs. This increase in the number of higher temperature disturbance events is likely to push a dense meadow initially located within the bistable depth range (1.6 to $1.8 \mathrm{~m}$ mean sea level) toward and eventually past a critical bifurcation point, from which recovery is not possible. We identified 2 leading indicators of a meadow nearing this bifurcation point, both associated with the number of leaves per shoot: 'flickering,' which reflects conspicuous fluctuations from one attractor to the other across the threshold, and 'slowing down,' which is the decreased recovery from perturbations as a system gets close to a threshold. Our model indicates that the eelgrass in these coastal bays has limited resilience to increases in water temperatures predicted from current climate change models.
\end{abstract}

KEY WORDS: Zostera marina $\cdot$ Seagrass $\cdot$ Climate change $\cdot$ Bistable dynamics $\cdot$ Ecosystem shifts Leading indicators

Resale or republication not permitted without written consent of the publisher

\section{INTRODUCTION}

While subtidal seagrass meadows and the surrounding salt marshes are highly productive ecosystems that provide critical ecosystem services, they are also susceptible to changes in nutrient, sediment, and freshwater delivery due to changes in anthropogenic land use and population density (Viaroli et al. 1996, Havens et al. 2001, Nixon et al. 2001). Increased water temperature and depth associated with climate change also pose potential threats to the health of seagrass meadows (Najjar et al. 2000, Cazenave et al. 2008, Keller 2009). The shallow depths of coastal bays provide a good environment for benthic primary productivity of species with high light requirements, such as seagrasses (Duarte 1991, Dennison et al. 1993, Zimmerman et al. 1995). However, these shallow depths also increase the vulnerability of the bed sediment to resuspension by waves and currents, which increases water column turbidity and 
adversely affects the light environment. In coastal bays that lack a significant river sediment supply, internal sediment resuspension is typically the dominant control on water column turbidity (Lawson et al. 2007).

The presence of seagrass reduces the wave and current shear stresses acting on the underlying bed sediment, thereby reducing resuspension and enhancing deposition of fine sediment (Folkard 2005). This can lead to less turbid waters and a more favorable light environment. This positive feedback, whereby a decrease in seagrass density decreases favorable light conditions, causing further loss of seagrass, has been shown to induce bistable dynamics (van der Heide et al. 2007, Carr et al. 2010). The emergence of bistability in ecosystems has important implications. Bistable systems exhibit nonlinear behavior in their response to environmental drivers, and can undergo rapid shifts between states due to only small changes in environmental conditions. Similarly, bistable systems are associated with limited resilience in that if the system is perturbed past a critical threshold, the system collapses to the alternate state (Wilson \& Agnew 1992). In this case, a seagrass meadow undergoing a disturbance exceeding a certain magnitude, duration, or frequency may pass into a state from which it cannot recover, resulting in loss of the seagrass meadow. The high turbidity environment of the now bare sediment inhibits establishment of new meadows, and the system remains locked in the alternate stable state, even if the disturbance is removed. Because of the abrupt and often irreversible character of these transitions, ecosystem managers need to be able to recognize whether a system is about to shift from a seagrass-covered bottom to a bare sediment state. However, such ecosystem shifts may or may not be associated with early warning signs (Hastings 2010). As such, it is important not only to identify the threshold between the 2 attraction domains (Brock \& Carpenter 2010), but also to recognize early warning signs, if they exist, that the system is about to cross the threshold between regimes.

It is difficult to predict these transition points because the state of the system may display little change prior to the transition (Scheffer et al. 2009). In some systems there is a critical slowing down effect (van Nes \& Scheffer 2007), whereby as the system approaches the bifurcation point, its response to small perturbations (i.e. small displacement from stable equilibrium) becomes increasingly slow. This slowing down results in an increased autocorrelation of the state variable and possibly an increase in variance when nearing the critical threshold (van Nes \& Scheffer 2007). Critical slowing down, increase in variance, or increase in autocorrelations have been shown to be suitable early warning signals of state change in some ecosystem and population dynamics (Litzow et al. 2008, Drake \& Griffen 2010, Carpenter et al. 2011) as well as in geophysical records (Dakos et al. 2008). Another possible symptom of being near the critical bifurcation point is flickering, which occurs when environmental or stochastic drivers are strong enough to induce relatively rapid oscillations between attraction domains of a system near the critical bifurcation point (Scheffer et al. 2001, 2009, Brock \& Carpenter 2010; Fig. 1). Regardless of the specific metric, evidence of a system being near catastrophic collapse is important for mitigation management practices, and also provides insight to guide and monitor successful restoration efforts. However, the sensitivity of these systems to natural and anthropogenic drivers complicates the development and implementation of successful management strategies.

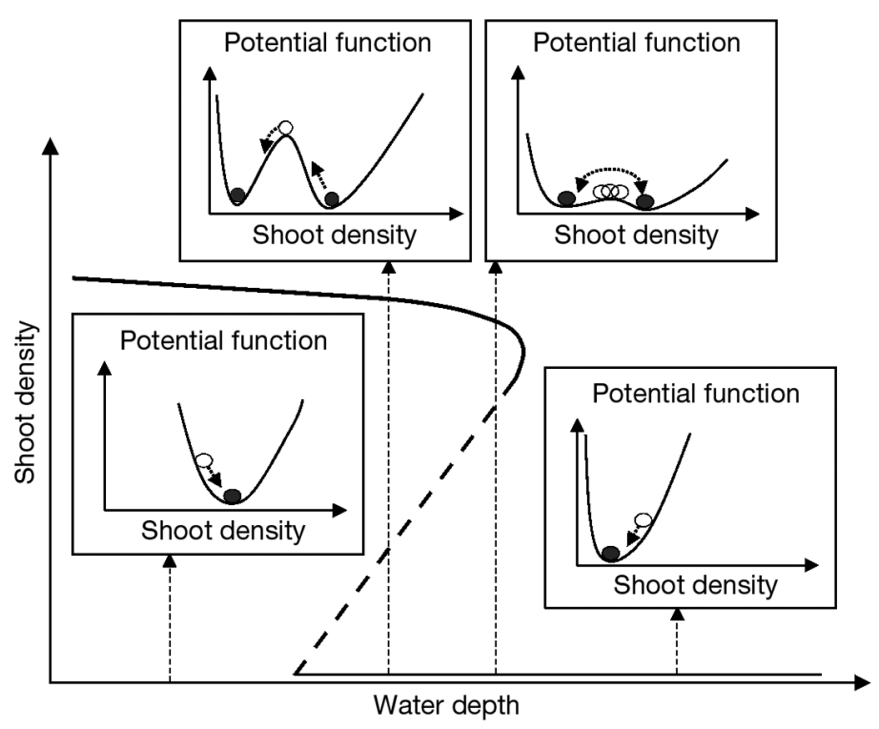

Fig. 1. Schematic representation of the 'fold-type' bifurcation of seagrass dynamics. Stable (solid) and unstable (dashed) states of the system are shown as a function of water depth. In shallow waters, the light environment is sufficient for seagrass establishment and survival regardless of the initial existence of a seagrass canopy stabilizing the benthic sediments. In relatively deep waters, the light penetrating the water column is insufficient for seagrass growth. In intermediate conditions, the system may be stable either with or without a seagrass bed. These stability and bistability conditions are shown in terms of minima of the potential function which is qualitatively plotted in the insets. Close to the critical fold bifurcation point, the potential barrier between the stable states is small, and the system may repeatedly fluctuate between these 2 states ('flickering'). (•) stable states; (O) unstable states 
To guide restoration and management efforts as well as to improve our understanding of the susceptibility of shallow coastal bays to changes in climate drivers and disturbances, including sea-level rise and temperature increase, we applied a coupled eelgrass growth and hydrodynamic model (Carr et al. 2012) to a set of scenarios reflecting expected future increases in sea level and water temperature in a shallow coastal bay. This model was used to investigate the strength of the feedback between water quality and eelgrass ecosystems, the impact of these feedbacks on the stability and resilience of estuarine seagrass meadows (van der Heide et al. 2007), and possible leading indicators of a ecosystem shift.

\section{MATERIALS AND METHODS}

\section{Study area}

The model was applied to coastal bays of the Virginia Coast Reserve Long Term Ecological Research (VCR LTER) site, located on the Atlantic side of the Delmarva Peninsula, USA $\left(37^{\circ} 25^{\prime} \mathrm{N}, 75^{\circ} 46^{\prime} \mathrm{W}\right)$. The coastal bays in this system were dominated by the seagrass Zostera marina (eelgrass) until the 1930s, when the eelgrasses, under stress from disease, were extirpated by a hurricane (Orth et al. 2006). Restoration efforts were prompted when small natural patches of eelgrass were discovered in the late 1990s. Eelgrass meadows now cover some 1700 ha in the VCR coastal bays (Orth et al. 2012, this Theme Section). Nutrient loading of the coastal bays is low and water column chlorophyll levels are also very low (Cole \& McGlathery this Theme Section; see also VCR LTER data base: www1.vcrlter.virginia.edu/ home1/?q=data_wq).

Hog Island Bay is representative of the shallow bays in the VCR, and is typical of coastal bay systems along the Atlantic and Gulf coasts, and served as our study site. Hog Island Bay has a tidal range of roughly $1.2 \mathrm{~m}$, with half of the bay $<1 \mathrm{~m}$ deep at mean low water (Oertel 2001). The sediment at the bay bottom ranges from fine sand to fine silt. Wind-driven resuspension dominates sediment transport in the bay, with dominant storms occurring from October to April (Lawson et al. 2007). Restored eelgrass meadows exist in Hog Island Bay between 0.6 and $1.6 \mathrm{~m}$ depths at mean sea level (MSL; McGlathery et al. 2012, this Theme Section). Locally, climate change is expected to generate a $30 \mathrm{yr}$ increase in MSL of $12 \mathrm{~cm}$ and an increase of $1.3^{\circ} \mathrm{C}$ in mean water temperature (Najjar et al. 2000).

\section{Modeling framework}

The model couples a hydrodynamic/light model (Carr et al. 2010) with a daily growth model (Carr et

Table 1. Eelgrass growth model, where ecosystem dynamics are represented through the following state variables: $N$ (total number of shoots), $P_{n, l}$ (biomass of leaf $l$ belonging to shoot $n$ ), and $R$ (rhizome biomass). The dynamics of these state variables are expressed by the following equations, with functions and parameters reported in Tables $2 \& 3$

\begin{tabular}{|c|c|}
\hline Equation & Description \\
\hline$\frac{\mathrm{d} N}{\mathrm{~d} t}=N\left(\max _{N g r o w} F_{\mathrm{I}}(I) F_{\text {phot }}(T) N_{\mathrm{lim}} R_{\mathrm{lim}}-N_{\text {loss }}\right)$ & $\begin{array}{l}\text { Change in the total number of shoots } N=\sum n \text {, where } n \text { is } \\
\text { an individual shoot, is a product of the total number of } \\
\text { shoots, and the difference between recruitment and loss }\end{array}$ \\
\hline$\frac{\mathrm{d} P_{n, I}}{\mathrm{~d} t}=P_{n, 1}\left(\max _{\mathrm{phot}} F_{\mathrm{I}}(I) F_{\text {phot }}(T) F_{\text {age }} P_{\text {lim }}-\max _{\mathrm{resp}} F_{\mathrm{T}}(T)\right)$ & $\begin{array}{l}\text { Change in biomass of leaf } l \text { belonging to shoot } n \text {, modeled } \\
\text { as a collection of up to } 4 \text { leaves }\left(l=\text { leaf number), with } P_{n, 0}\right. \\
\text { being the biomass of the stem }\end{array}$ \\
\hline$\frac{\mathrm{d} R}{\mathrm{~d} t}=k_{\text {transfer }} \sum_{n, l} \frac{\mathrm{d} P_{n, l}}{\mathrm{~d} t}-\gamma F_{\mathrm{T}}(T) R-{\frac{\mathrm{d} N_{n}}{\mathrm{~d} t}}^{+} P_{\text {nnew }, 0}+k_{\text {uproot }} \frac{\mathrm{d} N_{n}}{\mathrm{~d} t}$ & $\begin{array}{l}\text { Belowground biomass associated with the rhizome struc- } \\
\text { ture of eelgrass, } R \text {, is modeled as a bulk quantity with } \\
\text { rhizome growth due to translocation of above-ground } \\
\text { production, and loss due to respiration, translocation of } \\
\text { biomass to a new shoot, and loss of biomass to uprooting } \\
\text { when a shoot is lost }\end{array}$ \\
\hline$\frac{\mathrm{d} L_{n .1}}{\mathrm{~d} t}=\max _{\text {elong }} F_{\mathrm{I}}(I) F_{\text {phot }}(T) L_{\mathrm{lim}}$ & $\begin{array}{l}\text { Width and thickness are held constant, and change in the } \\
\text { length of leaf } l \text { of shoot } n, L_{n, l} \text { is modeled as a linear func- } \\
\text { tion of maximum leaf elongation rate, modulated by light, } \\
\text { and photosynthetic productivity as a function of tempera- } \\
\text { ture up to some maximum leaf length }\end{array}$ \\
\hline
\end{tabular}


Table 2. Limitation functions, description, and sources for the eelgrass growth model

\begin{tabular}{|c|c|c|}
\hline Limitation function & Description and values & Source \\
\hline$I=I_{\text {surface }} \mathrm{e}^{-K_{\mathrm{d}} h_{\mathrm{d}}}$ & $\begin{array}{l}\text { Irradiance at depth. } h_{\mathrm{d}} \text { is the distance from the } \\
\text { water surface to the deflected canopy. } K_{\mathrm{d}} \text { is the light } \\
\text { attenuation coefficient }\end{array}$ & Lawson et al. (2007) \\
\hline$I_{\mathrm{K}}=I_{\mathrm{K} 20} \theta_{\mathrm{K}}^{T-20}$ & $\begin{array}{l}\text { Saturation irradiance as a function of temperature. } \\
I_{\mathrm{K} 20} \text { is saturation value at } 20^{\circ} \mathrm{C} \text { set to } 25.5 \text { and } \theta_{\mathrm{K}} \text { is } \\
\text { shape value set to } 1.04\end{array}$ & Zharova et al. (2001) \\
\hline$I_{\mathrm{C}}=I_{\mathrm{C} 20} \theta_{\mathrm{K}}^{T-20}$ & $\begin{array}{l}\text { Compensation irradiance as a function of tempera- } \\
\text { ture. } I_{\mathrm{C} 20} \text { is compensation value at } 20^{\circ} \mathrm{C} \text { set to } 2.4 \\
\text { and } \theta_{\mathrm{C}} \text { is shape value set to } 1.17\end{array}$ & Zharova et al. (2001) \\
\hline $\begin{array}{l}F_{\mathrm{I}}(I)=0 \quad \text { for } \quad I \leq I_{\mathrm{C}} \\
F_{\mathrm{I}}(I)=1 \quad \text { for } \quad I \geq I_{\mathrm{K}} \\
F_{\mathrm{I}}(I)=\frac{I-I_{\mathrm{C}}}{I_{\mathrm{K}}-I_{\mathrm{C}}} \text { for } \quad I_{\mathrm{C}} \leq I \leq I_{\mathrm{K}}\end{array}$ & Light limitation function & Zharova et al. (2001) \\
\hline $\begin{array}{l}F_{\mathrm{phot}}(T)=K_{0 \mathrm{phot}}^{\left(\frac{T_{\mathrm{opt}-T}}{T_{\mathrm{opt}}}\right)^{2}} \text { for } T \leq T_{\mathrm{opt}} \\
F_{\mathrm{phot}}(T)=K_{\mathrm{mphot}}^{\left(\frac{T-T_{\mathrm{opt}}}{T_{\mathrm{max}}-T_{\mathrm{opt}}}\right)^{2}} \text { for } T>T_{\mathrm{opt}}\end{array}$ & $\begin{array}{l}\text { Temperature photosynthesis limitation function. } T_{\mathrm{opt}} \\
\text { is the optimum temperature for photosynthesis set to } \\
21.5^{\circ} \mathrm{C} . T_{\max } \text { is the maximum temperature for photo- } \\
\text { synthesis set to } 34^{\circ} \mathrm{C} \text {. } K_{0 \text { phot }} \text { is a shape coefficient set } \\
\text { to } 0.01 \text {, and } K_{\text {mphot }} \text { is a shape coefficient set to } \\
0.00001\end{array}$ & Zharova et al. (2001) \\
\hline $\begin{array}{l}F_{\text {age }}=1 \text { for ages } \leq \min _{\text {age }} \text { days and } P_{n, 0} \\
F_{\text {age }}=1-0.99\left(\text { age }-\min _{\text {age }}\right) /\left(\max _{\text {age }}-\min _{\text {age }}\right) \\
\text { for } \min _{\text {age }}<\text { ages } \leq \max _{\text {age }} \text { days } \\
F_{\text {age }}=0.01 \text { for ages }>\max _{\text {age }} \text { days }\end{array}$ & $\begin{array}{l}\text { Leaf age limitation function. } \\
\min _{\mathrm{age}}=70, \max _{\mathrm{age}}=175\end{array}$ & $\begin{array}{l}\text { Verhagen \& } \\
\text { Nienhuis (1983), } \\
\text { Hemminga \& Duarte } \\
(2000)\end{array}$ \\
\hline$F_{\mathrm{T}}(T)=\theta_{\text {loss }}^{T-20}$ & $\begin{array}{l}\text { Temperature respiration scaling function. } \theta_{\text {loss }} \text { is } \\
\text { shape value set to } 1.05\end{array}$ & Zharova et al. (2001) \\
\hline
\end{tabular}

al. 2012; Tables 1-3) and is used to estimate the annual and interannual morphology of a $1 \mathrm{~m}^{2}$ patch of a eelgrass meadow $1 \mathrm{~m}$ in from the edge of the meadow. Site measurements of peak shoot density, leaves shoot ${ }^{-1}$, leaf length, and above- to belowground biomass ratios were used to constrain model parameters (Table 3). The eelgrass growth model is built upon prior efforts to model eelgrass dynamics (Verhagen \& Nienhuis 1983, Zharova et al. 2001). The primary difference in our approach is that biomass is allocated and tracked by accounting for the distinct structural components (e.g. leaves and stem, where stem is defined as the rigid base of the shoot) for each shoot (Carr et al. 2012).

The hydrodynamic model (Carr et al. 2010) simulates the 1-dimensional dynamics (in the vertical direction) of sediment entrainment and settling within the water column on an hourly basis. It accounts for the effect of eelgrass vegetation on these dynamics, including its effect on the velocity profile, eddy diffusivity, shear-flow dispersion, and wave and current shear stress. At the same time it accounts for the effect of flow on the height of the deflected eelgrass canopy. Values of suspended sediment concentrations calculated by the model using a 1-dimensional advection diffusion equation are used to determine the degree of light attenuation within the water column (from the water surface to the top of the canopy, as in Lawson et al. 2007) and to calculate light availability for the eelgrass meadow.

Growth of the eelgrass meadow was modeled (Carr et al. 2012) based on available eelgrass data (Table 3), irradiance, and water temperature conditions in the VCR coastal bays. Eelgrass biomass is allocated among individual leaves and shoots, which transfer a fraction of aboveground production to a combined 
Table 3. Parameters and sources for the eelgrass growth model

\begin{tabular}{|c|c|c|}
\hline Parameter & Description and values & Source \\
\hline$\tau_{\mathrm{cr}}$ & Critical shear stress to erode sediment: $0.04 \mathrm{~Pa}$ & Lawson et al. (2007) \\
\hline $\max _{\text {resp }}$ & Respiratory loss rate: $0.014 \mathrm{~d}^{-1}$ & Bach (1993) \\
\hline $\max _{\mathrm{phot}}$ & Maximum specific growth rate: $0.095 \mathrm{~d}^{-1}$ & Bach (1993) \\
\hline $\max _{\text {elong }}$ & Maximum elongation rate: $0.00164 \mathrm{~m} \mathrm{~h}^{-1}$ & Kemp et al. (1987) \\
\hline $\max _{N g r o w}$ & Maximum shoot recruitment: $0.028 \mathrm{~d}^{-1}$ & Zharova et al. (2001) \\
\hline$N_{\text {loss }}$ & Shoot mortality rate: $0.0065 \mathrm{~d}^{-1}$ & Zharova et al. (2001) \\
\hline$L_{\lim }$ & Maximum leaf length limit, set to 1 if leaf length is $<1 \mathrm{~m}$, otherwise set to 0 & \\
\hline$R_{\lim }$ & $\begin{array}{l}\text { Above- to below-ground biomass ratio limitation, set to } 1 \text { if the ratio is } \\
<4.0 \text {, otherwise set to } 0\end{array}$ & $\begin{array}{l}\text { Site-specific } \\
\text { measurements }\end{array}$ \\
\hline$N_{\lim }$ & $N_{\text {lim }}=1-\left(\frac{N}{N_{\text {cc }}}\right)^{2} \begin{array}{l}\text { for } N \text { less than } N_{\mathrm{cc}} \text { otherwise set to } 0 . \text { Maximum shoot density, } \\
N_{\mathrm{cc}} \text { set to } 1000 \text { shoots } \mathrm{m}^{-2}\end{array}$ & \\
\hline$P_{\lim }$ & $\begin{array}{l}\text { Maximum biomass of a single leaf set to } 0.12 \mathrm{~g} \mathrm{C} \text { corresponding to a maximum } \\
\text { above-ground single shoot biomass of } 0.5 \mathrm{~g} \mathrm{C} \text { with } 4 \text { leaves of equal biomass }\end{array}$ & Zharova et al. (2001) \\
\hline$P_{\text {new }}$ & Biomass of a new shoot and single leaf set to $0.0024 \mathrm{~g} \mathrm{C}$ & Zharova et al. (2001) \\
\hline$\gamma$ & Rhizome respiration rate set to $0.009 \mathrm{~d}^{-1}$ & Zharova et al. (2001) \\
\hline Sparse meadow & 3 shoots $\mathrm{m}^{-2}, R=2 \mathrm{~g} \mathrm{C}, 3$ leaves shoot ${ }^{-1}, P=0.08 \mathrm{~g} \mathrm{C} \mathrm{leaf}^{-1}$ & \\
\hline Dense meadow & 640 shoots $\mathrm{m}^{-2}, R=45 \mathrm{~g} \mathrm{C} \sim 3$ leaves shoot ${ }^{-1}, P=0.09 \mathrm{~g} \mathrm{C} \mathrm{leaf}^{-1}$ & $\begin{array}{l}\text { Shoot density, leaves } \\
\text { shoot }{ }^{-1} \text { are site- } \\
\text { specific measurements }\end{array}$ \\
\hline
\end{tabular}

rhizome biomass. The growth model utilizes rhizome biomass storage to form a new shoot and leaf. Based on leaf productivity of that shoot, biomass is then transferred into new leaf growth, leaf elongation, and back to rhizome storage. Senescence of aboveground biomass is due to (1) leaves reaching a maximum age, (2) respiratory losses, and/or (3) shoot mortality. Rhizome biomass is lost due to (1) respiration, (2) new shoot recruitment, or (3) uprooting when a shoot is lost. The growth model is run on a daily basis with the modeled density of shoots and leaves above the sediment surface directly incorporated into the hydrodynamic model, influencing both the shear stress acting on the sediment surface as well as the mixing of sediment within the water column. As productivity is a direct function of water temperature and available irradiance (which, in turn, depends on suspended sediment concentration), the model was used to explore the effects of annual and interannual temperature and wave-current conditions on the resilience and stability of a eelgrass meadow.

For the eelgrass growth model, the parameter values used, descriptions, and limitation functions can be found in Tables 1 to 3. Model calibration was obtained by increasing the maximum shoot growth rate until maximum modeled daily shoot recruitment (Table 3) for repeated runs of the year 2001, which possessed the best growth characteristics, matched the maximum reported value of 14.4 shoots $\mathrm{m}^{-2} \mathrm{~d}^{-1}$ (Olesen \& Sand-Jensen 1994, Zharova et al. 2001). In general, the model was not sensitive to the calibration parameter (Carr et al. 2012), and the modeled maximum daily shoot recruitment for all years fell within the reported maximum range of 7 to 14.4 shoots $\mathrm{m}^{-2} \mathrm{~d}^{-1}$ (Olesen \& Sand-Jensen 1994).

Modeled peak shoot densities for dense meadows during randomized runs match observed values well, with measured dense meadows exhibiting peak modeled densities of around 650 shoots $\mathrm{m}^{-2}$. The model also captures well both the mean and variability in the measured peak shoot densities for re-establishing meadows (Carr et al. 2012). Similarly, modeled blade lengths correspond well to photographic measurements. In general, both modeled shoot densities and depth ranges align well with field observations in the restored seagrass meadows in Hog Island Bay (McGlathery et al. 2012). 


\section{Model simulations}

For any given year, hourly measured tides, winds, and water temperatures from the NOAA Wacha-

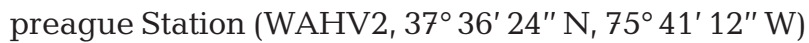
and photosynthetically active radiation (PAR) from the VCR-LTER flux tower at Fowling Point $\left(37^{\circ} 24^{\prime} \mathrm{N}\right.$, $75^{\circ} 50^{\prime} \mathrm{W}$ ) were used as external drivers for the model. For each $1 \mathrm{~h}$ time step, PAR reaching the canopy was calculated following Carr et al. (2010). Average daily water temperature and net daily PAR reaching the canopy were then used to drive the growth model on a daily time step. Summary statistics of growth conditions of the various years can be found in Table 4.

Supplied with a measured sediment grain size distribution, water depth relative to MSL, and a siterepresentative initial eelgrass meadow state of aboveand below-ground biomass and shoot and leaf densities (Table 3), the model calculated annual growth or senescence of the eelgrass within a meadow. The modeled meadow state at the end of any given year was used as the input meadow state for the following year, allowing us to model long-term changes in the meadow, investigate the ecosystem's stability and emergent bistability due to the hydrodynamic feedback, and explore how an expected $30 \mathrm{yr}$ increase in MSL of $12 \mathrm{~cm}$ and mean water temperature of $1.3^{\circ} \mathrm{C}$ (Najjar et al. 2000) will affect the stability of eelgrass meadows.

Years of forcing conditions (winds, tides, water temperature, and PAR) were selected from data records from 1996 through 2004 to form randomized 150 year-long sequences. Using these sequences at initial water depths ranging from 1.5 to $2.0 \mathrm{~m}$ MSL in $0.1 \mathrm{~m}$ increments, and by starting a meadow

Table 4. Comparison of days of above-ground biomass growth, loss, and days for exceeding $30^{\circ} \mathrm{C}$ under measured, and expected climate change conditions with an increase of $1.3^{\circ} \mathrm{C}$ based on temperature records for the years 1996 to 2004 for Zostera marina

\begin{tabular}{|ccccccc|}
\hline \multirow{2}{*}{ Year } & \multicolumn{3}{c}{ Days of growth } & \multicolumn{2}{c|}{ Days of loss } & \multicolumn{2}{c|}{ Days exceeding $30^{\circ} \mathrm{C}$} \\
& Measured & $+1.3^{\circ} \mathrm{C}$ & Measured & $+1.3^{\circ} \mathrm{C}$ & Measured & $+1.3^{\circ} \mathrm{C}$ \\
\hline 1996 & 247 & 232 & 119 & 133 & 15 & 47 \\
1997 & 288 & 271 & 77 & 94 & 18 & 47 \\
1998 & 285 & 265 & 80 & 100 & 11 & 43 \\
1999 & 302 & 292 & 63 & 73 & 5 & 37 \\
2000 & 334 & 311 & 31 & 54 & 0 & 9 \\
2001 & 309 & 307 & 56 & 58 & 0 & 0 \\
2002 & 301 & 283 & 64 & 82 & 11 & 39 \\
2003 & 276 & 269 & 89 & 96 & 0 & 19 \\
2004 & 280 & 246 & 85 & 119 & 2 & 30 \\
\hline
\end{tabular}

from both an initial dense and sparse meadow state (Table 3), we explored the attractors of the system (eelgrass meadow or bare sediment state) as a function of water depth and meadow state. To investigate the sensitivity of these attractors to sea-level rise and warming, 5 randomized $30 \mathrm{yr}$ sequences of forcing conditions were used to drive the model from an identical initial dense meadow of 640 shoots $\mathrm{m}^{-2}$, for the same depth range. Two of the five $30 \mathrm{yr}$ sequences were the same for all water depths to allow for direct behavioral comparison of how meadows initiated at different water depths react to identical sequences of environmental drivers. Averaging the 5 runs allowed for exploring the general behavior of the meadow. Three scenarios were explored in these simulations: (1) sea-level rise of $4 \mathrm{~mm} \mathrm{yr}^{-1}$ for $30 \mathrm{yr}^{\text {, }}$ (2) increase of $0.043^{\circ} \mathrm{C} \mathrm{yr}^{-1}$ in water temperature for $30 \mathrm{yr}$, and (3) combined sea-level rise and temperature increase for $30 \mathrm{yr}$ (Najjar et al. 2000).

\section{RESULTS \\ Overview}

Meadows initiated at depths between 1.6 and $1.8 \mathrm{~m}$ at MSL were found to display bistable behavior. Meadows initiated from a sparse canopy state were unable to grow in waters deeper than 1.6 m MSL. Shallower than $1.8 \mathrm{~m} \mathrm{MSL}$, meadows initiated from a dense meadow state were able to maintain a favorable light environment. Deeper than $1.8 \mathrm{~m} \mathrm{MSL}$, meadows initiated from both the sparse and dense states collapsed to the bare sediment state (Fig. 2). Meadows within the bistable range from 1.6 to $1.8 \mathrm{~m}$ MSL exhibited limited resilience such that a sequence of disturbances (years with poor light and temperature conditions) could shift a meadow into the attraction domain of the bare sediment state (Fig. 2). Thus, simulations aimed at exploring the effect of sealevel rise and increasing water temperatures were expected to show that meadows initialized at 1.5 and $1.6 \mathrm{~m}$ MSL remain dense under an increase in MSL of $4 \mathrm{~mm} \mathrm{yr}^{-1}$ for $30 \mathrm{yr}$ (total increase of $0.12 \mathrm{~m}$ ), whereas meadows initiated at $1.8 \mathrm{~m}$ MSL or deeper should show slow decline in shoot density. We also expected the meadow initiated at $2.0 \mathrm{~m}$ to decline, as at that water depth, the only attraction domain 


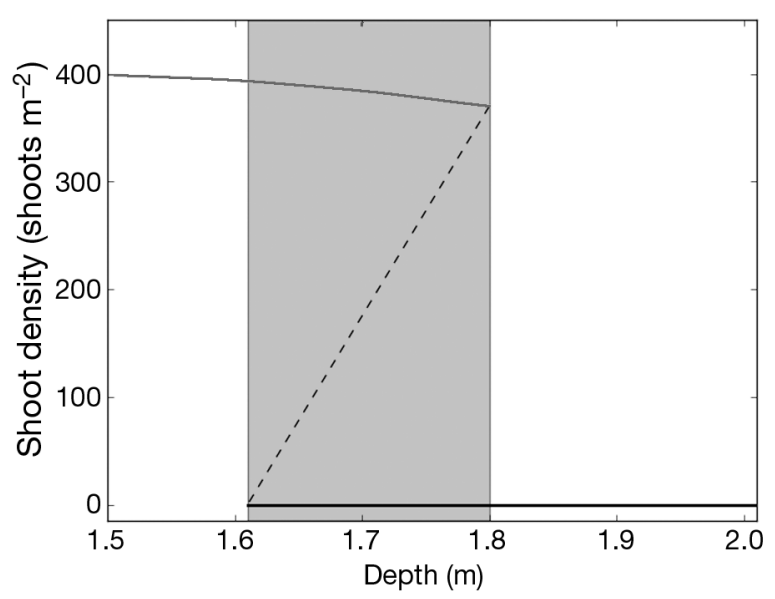

Fig. 2. Zostera marina. Fold bifurcation plot exhibiting the bistable depth range for $Z$. marina as a function of water depth and wintering shoot density (shoots $\mathrm{m}^{-2}$ ), under random drivers. Meadows at water shallower than $1.6 \mathrm{~m}$ mean sea level (MSL) exhibit a single attraction domain of a dense meadow state (gray line). Meadows initiated deeper than $1.8 \mathrm{~m}$ MSL display a single attraction domain of the bare sediment state (black line). In between 1.6 and $1.8 \mathrm{~m} \mathrm{MSL}$, depending on shoot density, depth and environmental forcing conditions, a meadow may be within the attractive domain of either the dense meadow state or the bare sediment state (shaded area)

of the dynamics is bare sediment. Similarly, across all water depths an increase in water temperature was expected to decrease net productivity of the eelgrass meadows with catastrophic losses when summer temperature exceeded $30^{\circ} \mathrm{C}$ for weeks at a time.

\section{Eelgrass stability and resilience under sea-level rise and warming scenarios}

Annual shoot densities were averaged for the 5 random $30 \mathrm{yr}$ simulations to examine the general effect of sea-level rise, increased temperature, and the combined effects of sea-level rise and temperature as a function of initial starting depth. Under sea-level rise only, for water depths of 1.5 and $1.8 \mathrm{~m} \mathrm{MSL}$, an extant meadow was present on average at the end of the 30 yr (Fig. 3a). Meadows initiated in deeper water on average showed a general slow decline, with 2 of the 5 meadows initiated at $2.0 \mathrm{~m}$ MSL collapsing to the bare sediment state by the end of the $30 \mathrm{yr}$ period. The meadows initiated at $1.9 \mathrm{~m}$ MSL did not begin to show decline until after $20 \mathrm{yr}$, with an extant, albeit declining, meadow for each of the 5 runs at the end of the 30 yr period (data not shown).

Increased water temperature caused meadows to experience sudden collapses sometime after $20 \mathrm{yr}$ due to the increased frequency of high summer temperature events (Table 4, Fig. 3b); this occurred for all water depths including some sequences at $1.5 \mathrm{~m}$ MSL (Fig. 4b). These collapses resulted in the abrupt loss of approximately 100 shoots in shallower water, with wholesale loss possible in water deeper than $1.7 \mathrm{~m}$ MSL. In 1 run (Fig. 4b), shoot loss at $1.5 \mathrm{~m}$ MSL occurred as a result of encountering 2 significant disturbance events (years with extremely poor growing conditions either due to storms and/or temperature) with only $3 \mathrm{yr}$ of recovery in between. These rapid losses are in contrast to the slow declines under just sea-level rise alone (Figs. 3a \& 4a). Initial depths less than $1.7 \mathrm{~m}$ MSL all displayed some residual meadow at the end of $30 \mathrm{yr}$, indicating still favorable growth conditions (i.e. the meadow remains in the attraction domain of a dense meadow). However, with increasing frequency and magnitude of disturbance due to increased temperature alone, it is unlikely that a dense meadow would be able to reestablish. Meadows initiated at $1.7 \mathrm{~m} \mathrm{MSL}$ and deeper exhibited collapse to bare sediment after a

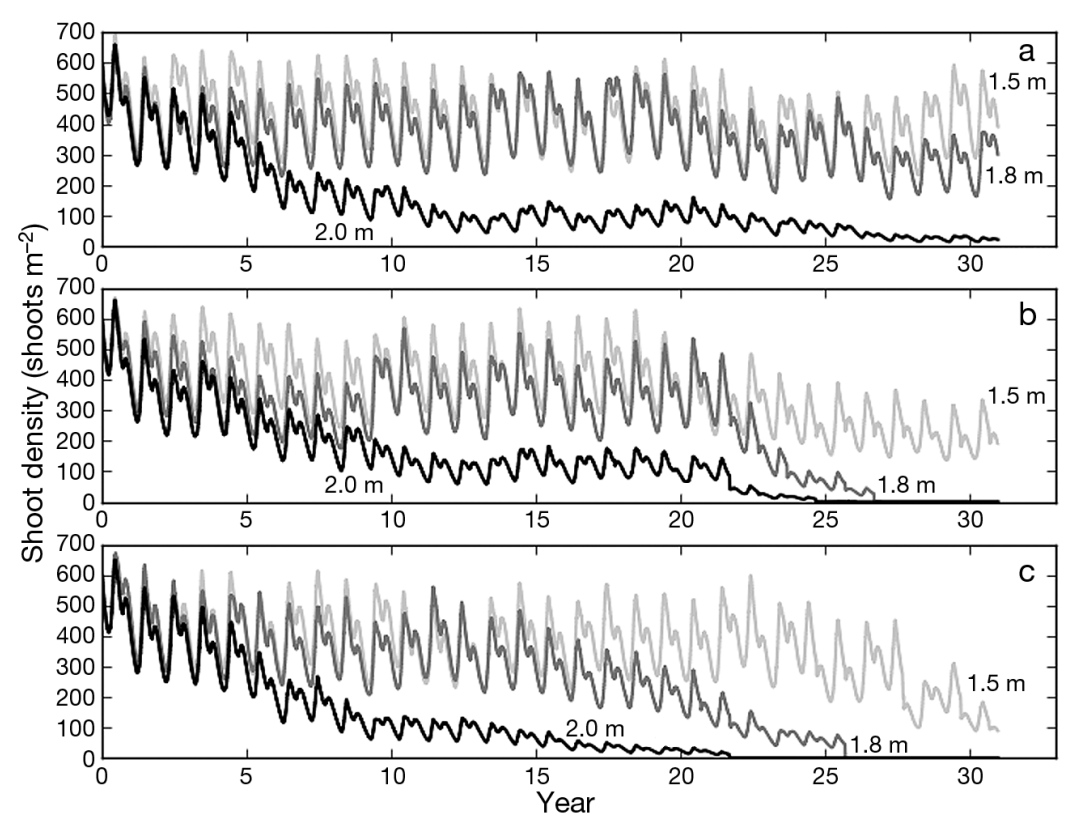

Fig. 3. Zostera marina. Shoot densities averaged over all runs initiated at water depths of 1.5, 1.8, and $2.0 \mathrm{~m}$ mean sea level, under (a) increase in sea level (b) increase in temperature, and (c) both increased temperature and sea level 


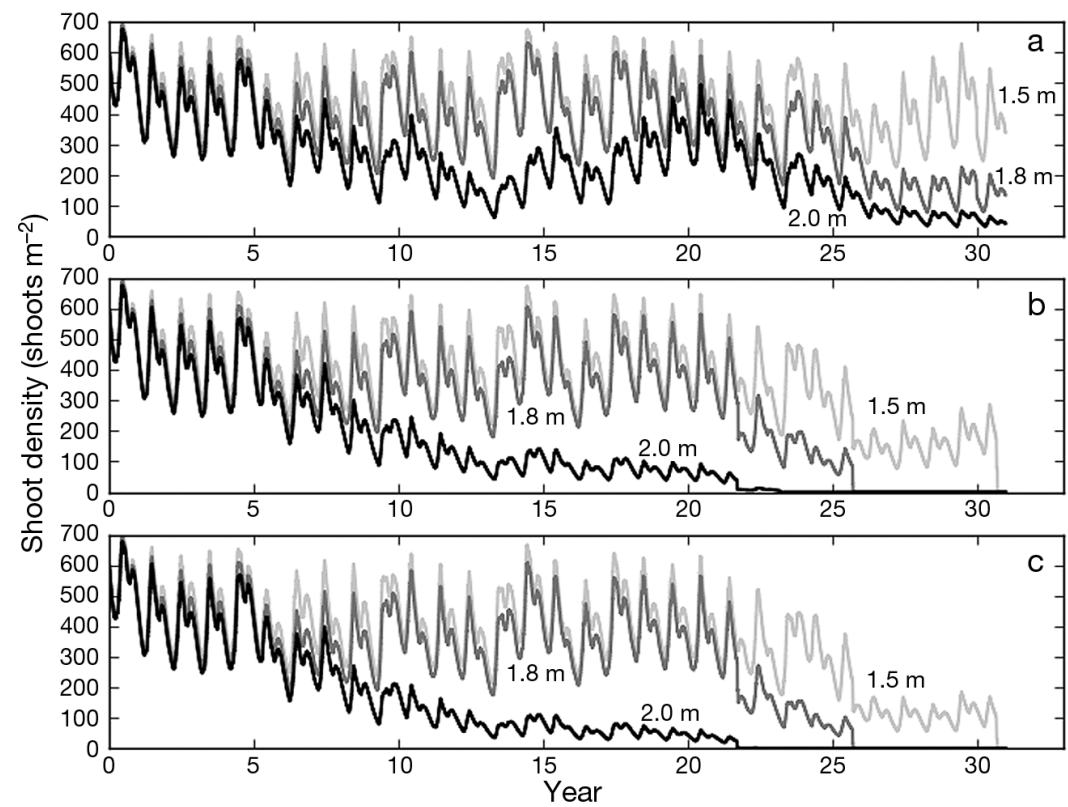

Fig. 4. Zostera marina. Shoot densities for run 4 initiated at water depths of 1.5, 1.8, and $2.0 \mathrm{~m}$ mean sea level, under (a) increase in sea level (b) increase in temperature, and (c) both increased temperature and sea level

Table 5. Years to collapse as a function of water depth (mean sea level, MSL) for the 5 model runs under combined conditions of sea-level rise and increased water temperature

\begin{tabular}{|lccccccc|}
\hline \multirow{2}{*}{ Run } & \multicolumn{7}{c|}{ Years to collapse } \\
\cline { 6 - 8 } & MSL depth: & $1.5 \mathrm{~m}$ & $1.6 \mathrm{~m}$ & $1.7 \mathrm{~m}$ & $1.8 \mathrm{~m}$ & $1.9 \mathrm{~m}$ & $2.0 \mathrm{~m}$ \\
\hline 1 & - & 28 & 28 & 24 & 21 & 17 \\
2 & 27 & 30 & 30 & 26 & 25 & 18 \\
3 & 30 & 27 & 26 & 26 & 24 & 22 \\
4 & 30 & 26 & 26 & 26 & 26 & 22 \\
5 & - & 26 & 26 & 24 & 23 & 23 \\
Mean & 29 & 27.4 & 27.2 & 25.2 & 23.8 & 20.4 \\
\hline
\end{tabular}

\section{Leading indicators of ecosystem shift}

We explored whether leading indicators of an ecosystem shift can be found in (1) the change in standard deviation of the number of leaves shoot $^{-1}$ for each day of the year and (2) trends in the mass distribution of empirical distribution functions (EDFs; Fig. 5) approaching the bifurcation point. This was done by examining the state variables and mass distribution of the number of leaves shoot ${ }^{-1}$ during the expected slow decline (Fig. 6a) of a meadow initiated at $2.0 \mathrm{~m}$ MSL undergoing sea-level rise. Unlike other authors (Carpenter 2006, Guttal \& Jayaprakash 2008), we did not find any leading indicators of state shift in standard deviation, skewness, or autocorrelation in the system state variables. While standard deviation and suitable metrics of multimodality increase as the system temporarily enters into the domain of attraction of bare sediment, these metrics were not good leading indicators of state change in that they did not exhibit any symptomatic changes as the system approached the bifurcation point. However, close to this point, eelgrass meadow behavior exhibited conspicuous fluctuations from one attractor to the other across the threshold, a phenomenon known as 'flickering' (Scheffer et al. 2009; our Figs. 1, 5, 6b) in the mass distribution of less than 2 leaves shoot $^{-1}$. Every time the system shifted

single disturbance event. In all cases, this significant disturbance event corresponded to years under increased temperatures where the duration of extremely high water temperatures in the summer months (Table 4) results in significant loss of leaves and shoots (Fig. 3b)

Under the combined increase in MSL and water temperature, meadows which fell into the bistable range between 1.6 and $1.8 \mathrm{~m}$ MSL when sea-level rise alone was considered, all collapsed to the bare state as a result of limited resilience to the now more frequent high-temperature events (Figs. 3c \& 4c). Time to collapse varied but was predominantly a function of initial meadow depth, with meadows in deeper waters being more susceptible (Table 5). into the domain of attraction of bare sediment, the probability distribution of the number of leaves shoot $^{-1}$ exhibited an increase at the lower leaf-pershoot end of the distribution (Figs. 5 \& 6b). This increase was due to leaf loss and/or high new shoot mortality. This conspicuous flickering was evident in collapsing meadows under increased temperature (Fig. 7) as well as those undergoing the combined effects of sea-level rise and temperature (Fig. 8). In comparison to a meadow in the stable attraction domain of the dense meadow state, a meadow near the critical bifurcation point, an increase the number of shoots with less than 2 leaves was not only larger but became more persistent until the meadow collapsed (Figs. $7 \mathrm{~b} \& \mathrm{8b}$ ). This increasing persistence is 
a typical indicator of a system slowing down close to a threshold due to its inability to recover (Scheffer et al. 2009). Under these conditions, a meadow as it approached the critical bifurcation point initially began to oscillate back and forth across the threshold. As the meadow neared the critical bifurcation

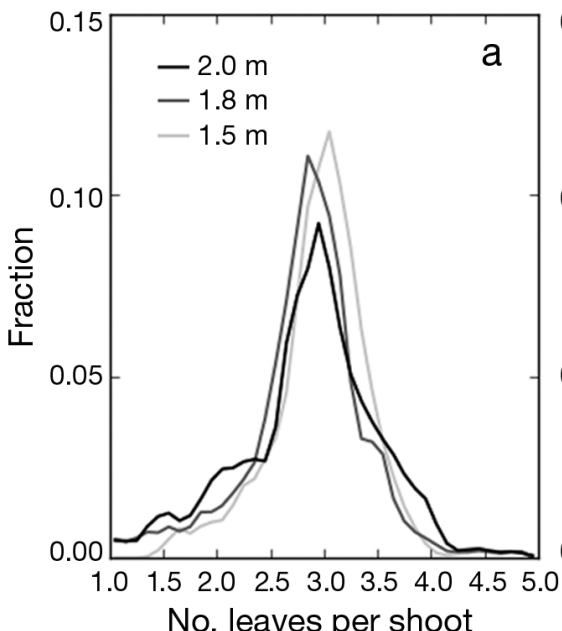

No. leaves per shoot

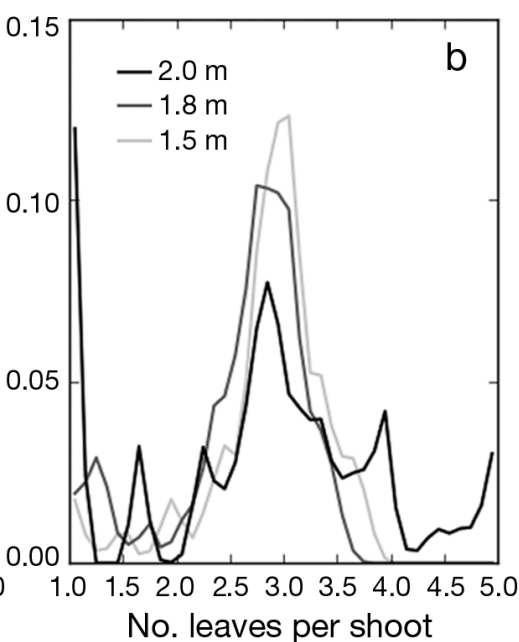

No. leaves per shoot
Fig. 5. Zostera marina. (a) Empirical distribution function (EDF) for number of leaves shoot ${ }^{-1}$ across all 5 sequences $(n=1357800)$ with increased sea-level rise for meadows initiated at 1.5, 1.8, and 2.0 m mean sea level (MSL). (b) Multimodal behavior and increase in the mass fraction $<2$ leaves shoot ${ }^{-1}$ in the EDF for meadows initiated at 1.5, 1.8, and $2.0 \mathrm{~m}$ MSL for an individual year $(\mathrm{n}=$ 8760) with poor growing conditions due to elevated temperatures
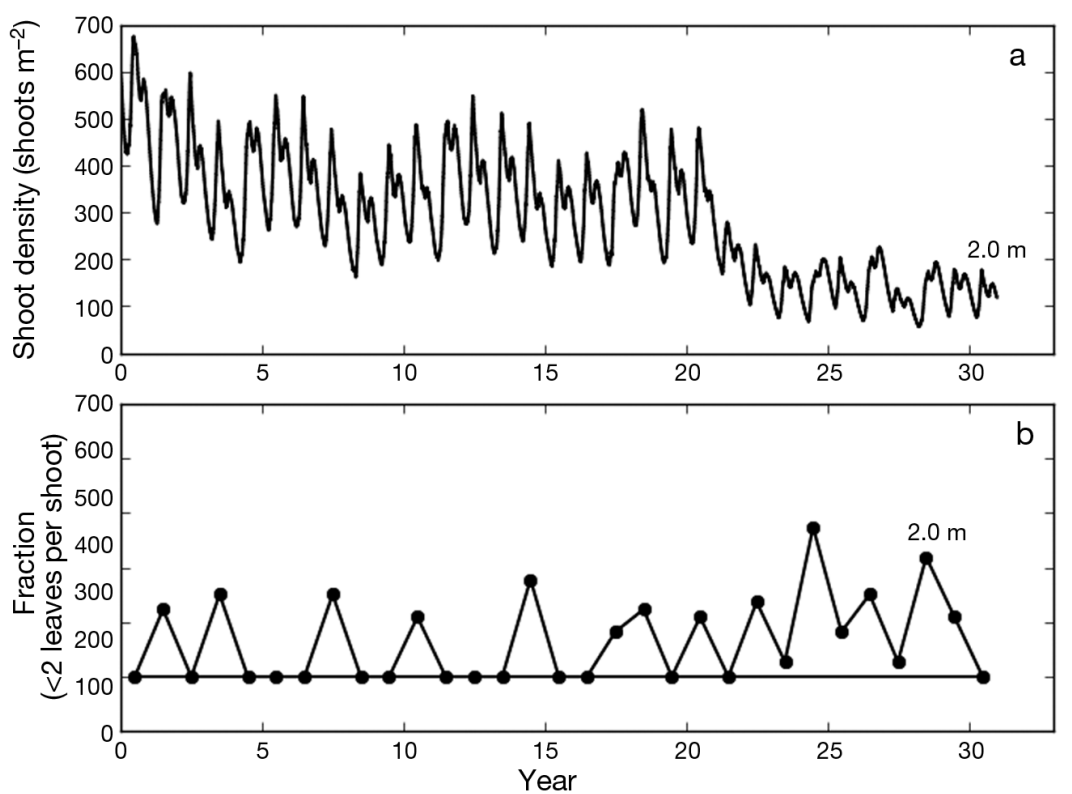

Fig. 6. Zostera marina. (a) Shoot densities for meadow initiated at $2.0 \mathrm{~m}$ mean sea level (MSL) under sea-level rise already within the attractive domain of the bare sediment state. (b) The evidence of flickering, in the fraction of mass $<2$ leaves shoot $^{-1}$ in the meadow initiated at $2.0 \mathrm{~m} \mathrm{MSL}$ under increasing sea-level rise point, it began to remain more frequently in the attractive domain of the bare sediment state (Figs. $7 \mathrm{~b}$ with a relatively persistent increase in the mass istribution of shoots with $<2$ leaves (Figs. 7b \& 8b). From this condition, the meadow was susceptible to fully crossing into an unrecoverable bare sediment state. Therefore, the emergence of substantial flickering (evidenced by oscillation in the mass distribution $<2$ leaves shoot $^{-1}$ ) followed by slowing down (evidenced by persistence and increase in the mass distribution $<2$ leaves $\operatorname{shoot}^{-1}$ ) appear to be leading indicators of proximity to a fold bifurcation.

\section{DISCUSSION}

Prior efforts have examined the loss of resilience, the existence of alternate stable states, and possible leading indicators of ecosystem shift in various systems (Gunderson 2000, Scheffer \& van Nes 2004). Here we demonstrate that the emergence of bistable dynamics due to the prior established positive feedback between seagrass and its light environment (de Boer 2007, van der Heide et al. 2007, Carr et al. 2010) plays an important role in the resilience of these meadows to the increased stresses of predicted climate change, namely sea-level rise and higher temperatures. The results indicate that while meadows shallower than 1.6 m MSL for our study site are currently stable and can be expected to remain within the stable light growth environment, the onset of increased water temperatures is likely to cause significant, but reversible collapse of these meadows. The expected effect of increased sea level is to push a meadow initially located within the attraction domain of a dense meadow towards the bistable depth range where the meadows will possess limited resilience. Frequent disturbances (e.g. years with poor growing conditions due to storms and/or high temperatures) may push the meadow into the attraction domain of the bare sedi- 

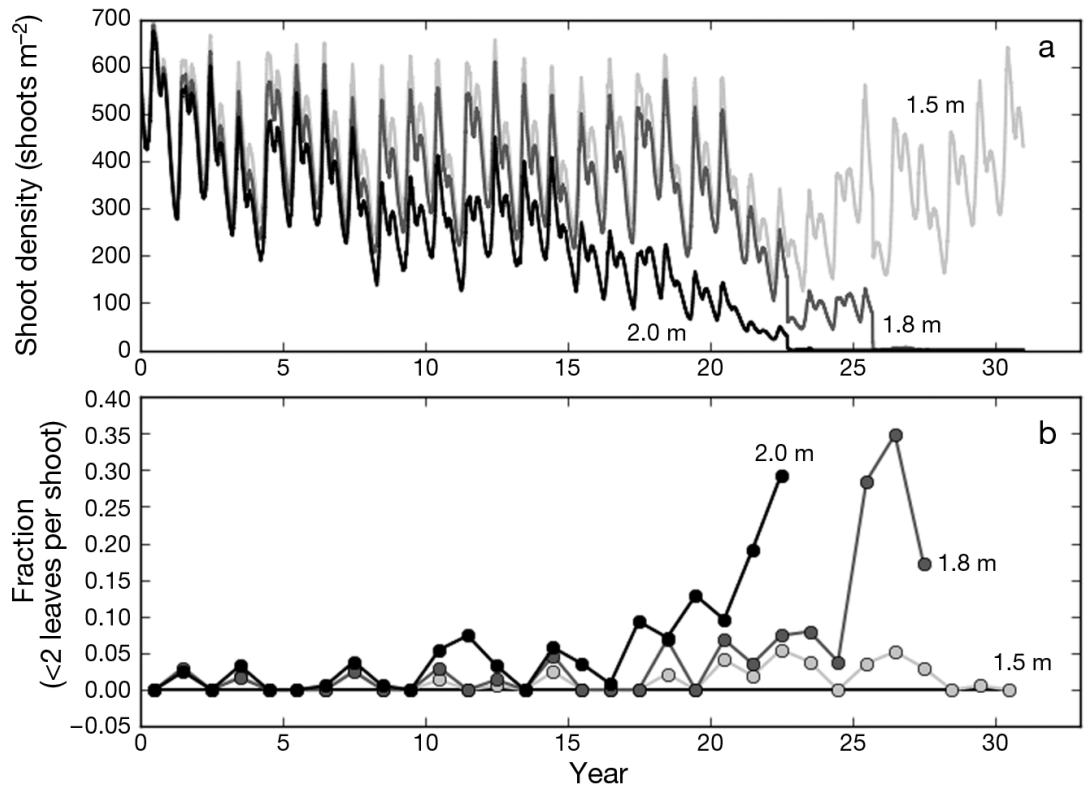

Fig. 7. Zostera marina. (a) Shoot densities for meadows initiated at 1.5, 1.8, and $2.0 \mathrm{~m}$ mean sea level (MSL) under increased temperature. (b) The appearance of flickering and slowing down prior to loss for the meadows initiated at 1.8 and $2.0 \mathrm{~m}$ MSL. Flickering, slowing down, but resilience of the meadow initiated at $1.5 \mathrm{~m} \mathrm{MSL}$
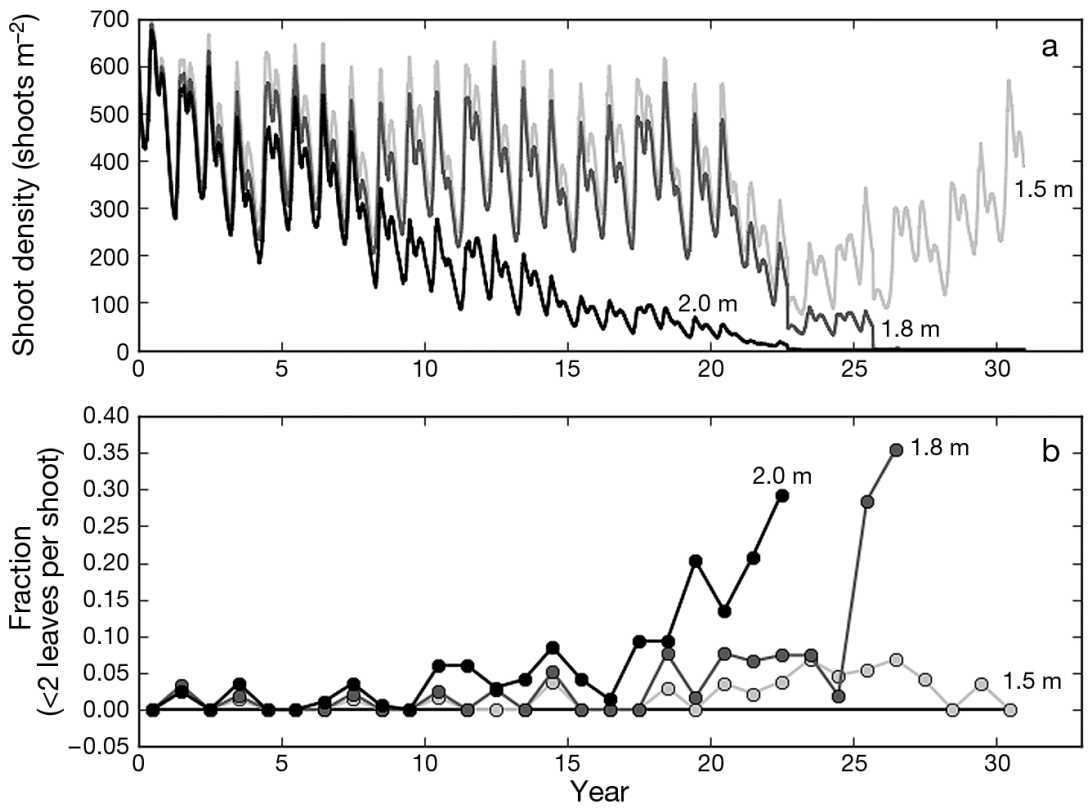

Fig. 8. Zostera marina. (a) Shoot densities for meadows initiated at 1.5, 1.8, and $2.0 \mathrm{~m}$ mean sea level (MSL) under increased temperature and sea level. (b) The appearance of flickering and slowing down prior to loss for the meadows initiated at 1.8 and $2.0 \mathrm{~m}$ MSL. Flickering, slowing down, but then recovery of the meadow initiated at $1.5 \mathrm{~m} \mathrm{MSL}$

ment state. Thus, as sea level increases, these meadows will begin to show limited resilience to disturbance events. Increases in water temperature (Moore \& Jarvis 2008) effectively increase the frequency of disturbances (e.g. years with poor growing conditions), as more years exhibit extended periods of high summer temperatures (Table 4 ) associated with significant die offs. As such, the more frequent occurrence of high-temperature events in the summer can rapidly push a meadow located within the bistable depth range past the critical bifurcation point and into the attraction domain of the bare sediment state from which irreversible collapse occurs. Sea-level rise alone can push a meadow into the attractive domain of the bare sediment state for depths that increase below the bistable range; however, collapse of these meadows is slow (Figs. 3a \& 4a) in contrast to the rapid losses brought about by summer high temperature events (Figs. 3b,c \& 4b,c).

Our results indicate that extant eelgrass meadows in the VCR LTER are unlikely to fail due to increases in sea-level rise alone, as rhizome branching rates and seed dispersal should be able to maintain migration of the meadows toward shallower waters. A benefit of sea-level rise for the eelgrasses in Hog Island Bay, which is a relatively undeveloped system with no significant riverine input (Oertel 2001), is that the area of suitable habitat (area deeper than $0.6 \mathrm{~m}$ MSL and shallower than $1.6 \mathrm{~m}$ MSL) will increase over the next 30 yr based on hypsometry (Fig. 9). The area of the bay exhibiting bistable behavior (area between 1.6 and $1.8 \mathrm{~m} \mathrm{MSL}$ ) will also increase. However, the results also indicate that the eelgrass meadows of the VCR LTER are likely to undergo severe die-offs due to extended summer periods with increased water temperatures. This is consistent with observed high temperature effects on Zostera marina (Duarte 2002, Moore \& Jarvis 2008, Moore et al. 2012, this Theme Section). The temperature is projected to increase from 1 to $1.5^{\circ} \mathrm{C}$ in $30 \mathrm{yr}$ with a projected 2.7 to $5.5^{\circ} \mathrm{C}$ increase by 2095 (Najjar et al. 2000). Even a modest 


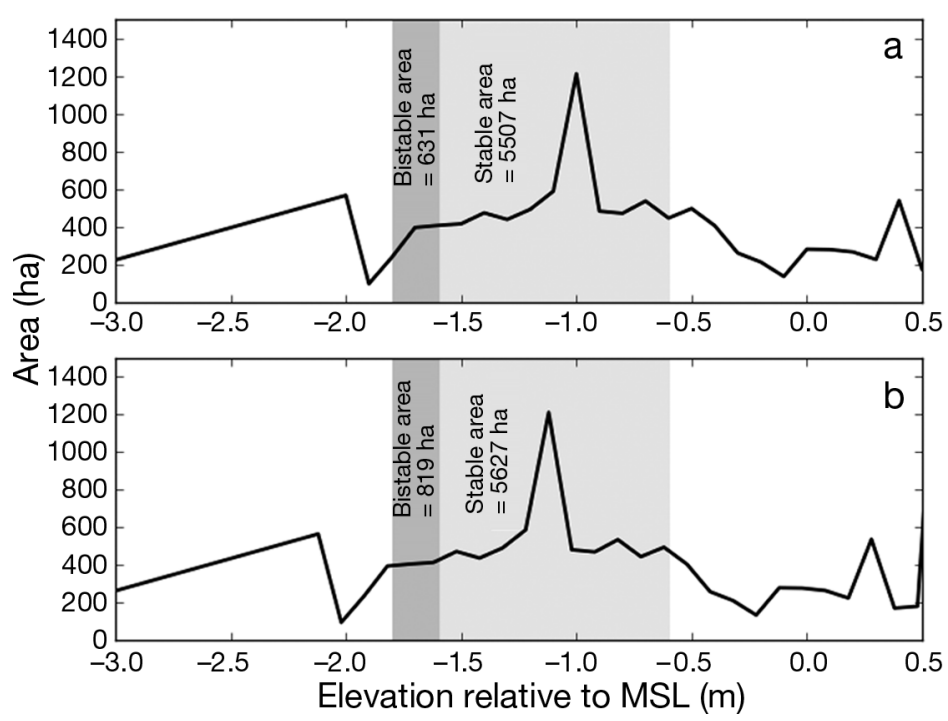

Fig. 9. (a) Current area of Hog Island Bay suitable for eelgrass establishment or maintenance. (b) Increase in suitable area under an increase in sea level of $0.12 \mathrm{~m}$ in $30 \mathrm{yr}$

increase in water temperature can result in significant changes in compensation light requirements (Moore et. al. 2012) and can result in large changes in the trajectories of $Z$. marina expansion. As such, with the projected continued increase in water temperature, eventually the coastal bays of the VCR will not be suitable habitat for $Z$. marina. Thus, while the meadows are able to moderate their light environment and increasing sea level increases the total area of suitable habitat, an increase in water temperature is likely to have significant and catastrophic effects.

From the ecosystem management standpoint, knowledge of whether seagrass meadows are approaching a bifurcation point is crucial to timely seagrass conservation efforts. A bifurcation point is not readily measureable or identifiable, as it is a function of both the current meadow state and the environmental drivers. As such, we attempted to identify what traits an eelgrass meadow exhibits when it approaches or crosses the transition point to the bare sediment state. We focused on meadow characteristics that are non-destructive and easily measured, such as leaf density, shoot density, and number of leaves shoot ${ }^{-1}$. We found that while density metrics are not adequate to predict the location of the critical bifurcation point, the number of leaves shoot ${ }^{-1}$ for a meadow may be a useful indicator.

Comparing simulations of eelgrass meadows initiated at depths of 1.5, 1.8, and $2.0 \mathrm{~m}$ MSL experiencing the same sequence of randomized forcing under varying temperature and sea-level conditions allowed us to examine the dynamics of shoot and leaf populations in stable meadows, bistable beds, and stable bare sediment regimes. Similarly, this allowed for investigation of leading indicators of an ecosystem shift as the meadows approach the depth for which they fall within the attractive domain of the bare sediment state. The EDFs of the number of leaves shoot ${ }^{-1}$ calculated in an individual year exhibited multimodal behavior, particularly when a meadow was under duress (Fig. 4b). Multimodality tended to disappear in the case of dense meadows. This is comparable to a change in properties of the state variables' distribution, such as variance or skewness, witnessed in some systems (Carpenter 2006, Guttal \& Jayaprakash 2008). Similarly, the emergence of significant multimodality can be considered as an indicator of eelgrass stress. This multimodality may happen for various reasons: in some cases, it is due to a year when all the young shoots established but were continuously being lost, while the 'middle-aged' shoots were able to increase leaf density, thereby creating a multimodal distribution. Alternatively, the occurrence of multiple modes may be due to patterns of eelgrass loss and regrowth associated with the seasonal cycle. The presence of multimodal distributions in the number of leaves shoot ${ }^{-1}$ generally resulted in a larger standard deviation in leaves shoot ${ }^{-1}$.

The measures of stability investigated herein allow for the possibility of non-destructive monitoring of the viability of extant eelgrass meadows, through repeated sampling to assess leaf and shoot counts. The emergence of annual multimodality and a significant decrease in the variability of number of leaves shoot $^{-1}$ are indicators of stress and possible future collapse. Synoptic sampling of these parameters within a year and cross comparison of years would allow for identification of the flickering or persistent increase in the number of shoots with low leaf counts that may be indicative of being close to the threshold of collapse.

Our approach assumed a constant linear increase in both local relative sea-level rise and water temperature. For the 30 yr considered in this study, a linear increase is an acceptable approximation. However, the omission of possible increases in storminess must be noted. Increased storminess (Hayden 1999) is likely to increase light stress due to enhanced resuspension, especially since eelgrass has less of an effect on the attenuation of near bed wave orbital velocities than current velocities (Luhar 2010). Re- 
garding the effects of climate change and the identification of leading indicators of collapse, the model is primarily limited by the length of available data sets of environmental drivers; however, the strong symptoms of flickering and slowing down were robust across all model simulations.

While the detailed coupled model used in this study provides many insights into the stability, bistability, and indicators of meadow stress and collapse, there are limitations. The vegetation growth model is sensitive to temperature (Zharova et al. 2001, Pastres et al. 2004), due to the involvement of temperature both in the saturation irradiance compensation curves as well as photosynthetic and respirations rates. Summer die-offs due to high temperature are typically observed when the water temperatures exceed $30^{\circ} \mathrm{C}$ for a long period of time in July and August (Moore \& Jarvis 2008). The modeled values indicate this temperature threshold to be around $28.5^{\circ} \mathrm{C}$, and as such, effects of temperature modeled herein may be overestimated. If so, however, these results would hold for a period in time further in the future in terms of increased water temperature. Other vegetation growth parameters in the model such as leaf elongation rates, labile to structural carbon ratios, and biomass characteristics of the various plant structures could be adapted to be more site specific. Regardless, modeled shoot densities and depth ranges align well with field observations in the restored eelgrass meadows in Hog Island Bay where the maximum depth limit of eelgrass was found to be $1.6 \mathrm{~m} \mathrm{MSL}$, matching the limit of the stable distribution predicted by the model (McGlathery et al. 2012).

\section{CONCLUSIONS}

Both water temperature and the emergence of bistable dynamics due to the positive feedback between eelgrasses and their light environment play important roles regarding the survivability of eelgrass meadows. Eelgrass that fall within the bistable depth range display limited resilience to increased environmental stressors associated with climate change. Eelgrass meadows shallower than this bistable range can withstand the increased sea-level projections for the next $30 \mathrm{yr}$, as will meadows at the shallower end of the bistable range. Meadows at the deeper end of the bistable range will be pushed into the attraction domain of the bare sediment state. Increases in water temperature will likely result in more frequent and severe high summer temperature stress resulting in significant summer die-offs for meadows at all depths. Meadows within the bistable depth range displayed limited resilience, and as they decreased in density, they approached the critical bifurcation point beyond which the meadows were unable to recover. Both flickering and slowing down are seen as leading indicators of collapse.

Acknowledgements. Partial support for this study was provided by the Virginia Coast Reserve LTER project, which was supported by National Science Foundation grant DEB0621014.

\section{LITERATURE CITED}

Bach HK (1993) A dynamic model describing the seasonal variations in growth and the distribution of eel grass (Zostera marina). Ecol Model 65:31-50

Brock WA, Carpenter SR (2010) Interacting regime shifts in ecosystems: implication for early warnings. Ecol Monogr 80:353-367

Carpenter SR (2006) Rising variance: a leading indicator of ecological transition. Ecol Lett 9:311-318

Carpenter SR, Cole JJ, Pace ML, Batt R and others (2011) Early warnings of regime shifts: a whole-ecosystem experiment. Science 332:1079-1082

Carr J, D'Odorico P, McGlathery K, Wiberg PL (2010) Stability and bistability of seagrass ecosystems in shallow coastal lagoons: role of feedbacks with sediment resuspension and light attenuation. J Geophys Res 115:G03011 doi:10.1029/2009JG001103

Carr J, D'Odorico P, McGlathery K, Wiberg PL (2012) Stability and resilience of seagrass meadows to seasonal and interannual dynamics and environmental stress. J Geophys Res 117:G01007 doi:10.1029/2011JG001744

> Cazenave A, Lombard A, Llovel W (2008) Present-day sea level rise: a synthesis. C R Geosci 340:761-770

> Cole LW, McGlathery KJ (2012) Nitrogen fixation in restored eelgrass meadows. Mar Ecol Prog Ser 448:235-246

> Dakos V, Scheffer M, van Nes EH, Brovkin V, Petoukhov V, Held H (2008) Slowing down as an early warning signal for abrupt climate change. Proc Natl Acad Sci USA 105: 14308-14312

de Boer WF (2007) Seagrass-sediment interactions, positive feedbacks and critical thresholds for occurrence: a review. Hydrobiologia 591:5-24

Dennison WC, Orth RJ, Moore KA, Stevenson JC and others (1993) Assessing water-quality with submersed aquatic vegetation. Bioscience 43:86-94

Drake JM, Griffen BD (2010) Early warning signals of extinction in deteriorating environments. Nature 467:456-459

> Duarte CM (1991) Seagrass depth limits. Aquat Bot 40: 363-377

> Duarte CM (2002) The future of seagrass meadows. Environ Conserv 29:192-206

> Folkard AM (2005) Hydrodynamics of model Posidonia oceanica patches in shallow water. Limnol Oceanogr 50: 1592-1600

> Gunderson LH (2000) Ecological resilience-in theory and application. Annu Rev Ecol Syst 31:425-439

> Guttal V, Jayaprakash C (2008) Changing skewness: an early warning signal of regime shifts in ecosystems. Ecol Lett 11:450-460 
Hastings A (2010) Regime shifts in ecological systems can occur with no warning. Ecol Lett 13:464-472

- Havens KE, Hauxwell J, Tyler AC, Thomas S and others (2001) Complex interactions between autotrophs in shallow marine and freshwater ecosystems: implications for community responses to nutrient stress. Environ Pollut 113:95-107

Hayden BP (1999) Climate change and extratropical storminess in the United States: an assessment. J Am Water Resour Assoc 35:1387-1397

Hemminga M, Duarte CM (2000) Seagrass ecology, Cambridge University Press, Cambridge

Keller CF (2009) Global warming: a review of this mostly settled issue. Stochastic Environ Res Risk Assess 23: 643-676

Kemp W, Murray L, Borum J, Sand-Jensen K (1987) Diel growth in eelgrass Zostera marina. Mar Ecol Prog Ser 41: 79-86

Lawson SE, Wiberg PL, McGlathery KJ, Fugate DC (2007) Wind-driven sediment suspension controls light availability in a shallow coastal lagoon. Estuar Coasts 30: 102-112

Litzow MA, Urban JD, Laurel BJ (2008) Increased spatial variance accompanies reorganization of two continental shelf ecosystems. Ecol Appl 18:1331-1337

Luhar M (2010) Wave-induced velocities inside a model seagrass bed. J Geophys Res 115:C12005, doi:10.1029/ 2010JC006345

McGlathery KJ, Reynolds LK, Cole LW, Orth RJ, Marion SR, Schwarzschild A (2012) Recovery trajectories during state change from bare sediment to eelgrass dominance. Mar Ecol Prog Ser 448:209-221

Moore KA, Jarvis JC (2008) Environmental factors affecting recent summertime eelgrass diebacks in the lower Chesapeake Bay: implications for long-term persistence. J Coast Res (Spec Issue) 55:135-147

> Moore KA, Shields EC, Parrish DB, Orth RJ (2012) Eelgrass survival in two contrasting systems: role of turbidity and summer water temperatures. Mar Ecol Prog Ser 448: 247-258

Najjar RG, Walker HA, Anderson PJ, Barron EJ and others (2000) The potential impacts of climate change on the mid-Atlantic coastal region. Clim Res 14:219-233

Nixon S, Buckley B, Granger S, Bintz J (2001) Responses of very shallow marine ecosystems to nutrient enrichment. Hum Ecol Risk Assess 7:1457-1481

Oertel G (2001) Hypsographic, hydro-hypsographic and

Submitted: June 15, 2011; Accepted: December 9, 2011 hydrological analysis of coastal bay environments, Great Machipongo Bay. J Coast Res 17:775-783

Olesen B, Sand-Jensen K (1994) Biomass-density patterns in the temperate seagrass Zostera marina. Mar Ecol Prog Ser 109:283-291

Orth RJ, Luckenbach ML, Marion SR, Moore KA, Wilcox DJ (2006) Seagrass recovery in the Delmarva Coastal Bays, USA. Aquat Bot 84:26-36

Orth RJ, Moore KA, Marion SR, Wilcox DJ, Parrish DB (2012) Seed addition facilitates eelgrass recovery in a coastal bay system. Mar Ecol Prog Ser 448:177-195

Pastres R, Brigolin D, Petrizzo A, Zucchetta M (2004) Testing the robustness of primary production models in shallow coastal areas: a case study. Ecol Model 179:221-233

> Scheffer M, van Nes EH (2004) Mechanisms for marine regime shifts: Can we use lakes as microcosms for oceans? Prog Oceanogr 60:303-319

Scheffer M, Carpenter S, Foley JA, Folke C, Walker B (2001) Catastrophic shifts in ecosystems. Nature 413:591-596

Scheffer M, Bascompte J, Brock WA, Brovkin V and others (2009) Early-warning signals for critical transitions. Nature 461:53-59

van der Heide T, van Nes EH, Geerling GW, Smolders AJP, Bouma TJ, van Katwijk MM (2007) Positive feedbacks in seagrass ecosystems: implications for success in conservation and restoration. Ecosystems 10:1311-1322

van Nes EH, Scheffer M (2007) Slow recovery from perturbations as a generic indicator of a nearby catastrophic shift. Am Nat 169:738-747

> Verhagen JHG, Nienhuis PH (1983) A simulation model of production, seasonal changes in biomass and distribution of eelgrass (Zostera marina) in Lake Grevelingen. Mar Ecol Prog Ser 10:187-195

Viaroli P, Bartoli M, Bondavalli C, Christian RR, Giordani G, Naldi M (1996) Macrophyte communities and their impact on benthic fluxes of oxygen, sulphide and nutrients in shallow eutrophic environments. Hydrobiologia 329:105-119

Wilson JB, Agnew ADQ (1992) Positive-feedback switches in plant communities. Adv Ecol Res 23:263-336

Zharova N, Sfriso A, Voinov A, Pavoni B (2001) A simulation model for the annual fluctuation of Zostera marina biomass in the Venice lagoon. Aquat Bot 70:135-150

Zimmerman RC, Reguzzoni JL, Alberte RS (1995) Eelgrass (Zostera marina L.) transplants in San Francisco Bayrole of light availability on metabolism, growth and survival. Aquat Bot 51:67-86

Proofs received from author(s): January 30, 2012 